Review Articles

\title{
Estimated Acrylamide Intake from Coffee Consumption in Latin America
}

\author{
${ }^{1}$ Ana Carolina Vieira Porto, ${ }^{1,2}$ Otniel Freitas-Silva, \\ ${ }^{2,3}$ Jeane Santos da Rosa and ${ }^{2}$ Leda Maria Fortes Gottschalk \\ ${ }^{I}$ Department of Food Technology, Nutrition School, \\ Food and Nutrition Postgraduate Program, Federal University of Rio de Janeiro State- UNIRIO, \\ Av. Pasteur, 296, Urca, 22290-240, Rio de Janeiro, Brazil \\ ${ }^{2}$ Embrapa Food Technology, Av das Américas, 29501, 23.020-470, Rio de Janeiro, Brazil \\ ${ }^{3}$ Food Science Department, Institute of Chemistry, \\ Federal University of Rio de Janeiro, Cidade Universitária, 21941-909, Rio de Janeiro, Brazil
}

\section{Article history}

Received: 18-05-2015

Revised: 26-05-2015

Accepted: 18-6-2015

Corresponding Author: Otniel Freitas-Silva

Embrapa Food Technology, Av das Américas, 29501, 23.020-

470, Rio de Janeiro, Brazil

Tel: $+55(21) 3622-9645$;

Fax: $+55(21) 3622-9713$
Email: otniel.freitas@embrapa.br

\begin{abstract}
The presence of acrylamide in foods such as coffee can pose risks to human health. Coffee consumption and production in Latin America have increased in recent years. According to the FAO, world coffee consumption is divided into five groups of countries according to average yearly per capita consumption: (i) between $8.0 \mathrm{~kg}$ and $12 \mathrm{~kg}$; (ii) between $4.1 \mathrm{~kg}$ and $8.0 \mathrm{~kg}$; (iii) between $2.4 \mathrm{~kg}$ and $4.5 \mathrm{~kg}$; (iv) between 0.8 $\mathrm{kg}$ and $2.4 \mathrm{~kg}$; and (v) less than $0.8 \mathrm{~kg}$. In this work, the countries of Latin America are divided into three groups according to annual per capita coffee consumption: group 1: between $4.1 \mathrm{~kg}$ and $8.0 \mathrm{~kg}$ (Brazil, Argentina, Colombia and Costa Rica); group 2: between $2.4 \mathrm{~kg}$ and $4.5 \mathrm{~kg}$ (Guyana, French Guyana, Honduras, Suriname, Uruguay and Venezuela); and group 3: between $0.8 \mathrm{~kg}$ and $2.4 \mathrm{~kg}$ (Bolivia, Chile, Cuba, El Salvador, Ecuador, Guatemala, Haiti, Jamaica, Mexico, Nicaragua, Panama, Paraguay, Peru, Puerto Rico and Dominican Republic). There are great differences in the consumption of acrylamide-forming foods among populations from different countries. The literature shows a range from 0.5 to $4.21 \mu \mathrm{g}$ of acrylamide per $300 \mathrm{~mL}$ of coffee and the World Health Organization recommends a maximum daily limit for acrylamide intake of $1 \mu \mathrm{g} / \mathrm{kg} \mathrm{bw}$. Thus, coffee is a beverage that contributes greatly to acrylamide intake in almost all population groups. From the calculated data on acrylamide intake in Latin America, it was possible to estimate the daily intake in the region's countries. According to the maximum limit set by the WHO of $1 \mu \mathrm{g}$ acrylamide per day per bw, for people in the countries of group 1, coffee makes a large contribution to the intake of acrylamide. Thus, there should be focus on reducing the levels of acrylamide in foods, since they are the predominant sources of this substance for some populations.
\end{abstract}

Keywords: Coffea Arabica, Coffea Canephora, Coffee Production, Food Safety

\section{Introduction}

Acrylamide has attracted concern by public authorities all over the world (Zhang et al., 2005; Friedman, 2003). It is a chemical compound (Fig. 1) used to synthesize polyacrylamide. Its chemical structure was first identified in fried potatoes and it began to be studied in 2002 by Swedish scientists. Various studies have been conducted to determine the origin of acrylamide in foods. The previously known sources, such polyacrylamides and heating of organic matter, have been discarded. Some processed foods have been identified since then as the main sources of this substance in the human diet. The potential routes of human exposure to acrylamide are ingestion, skin contact and inhalation. One of the oral exposure routes is via drinking water contaminated by polyacrylamide flocculants used in water treatment. 


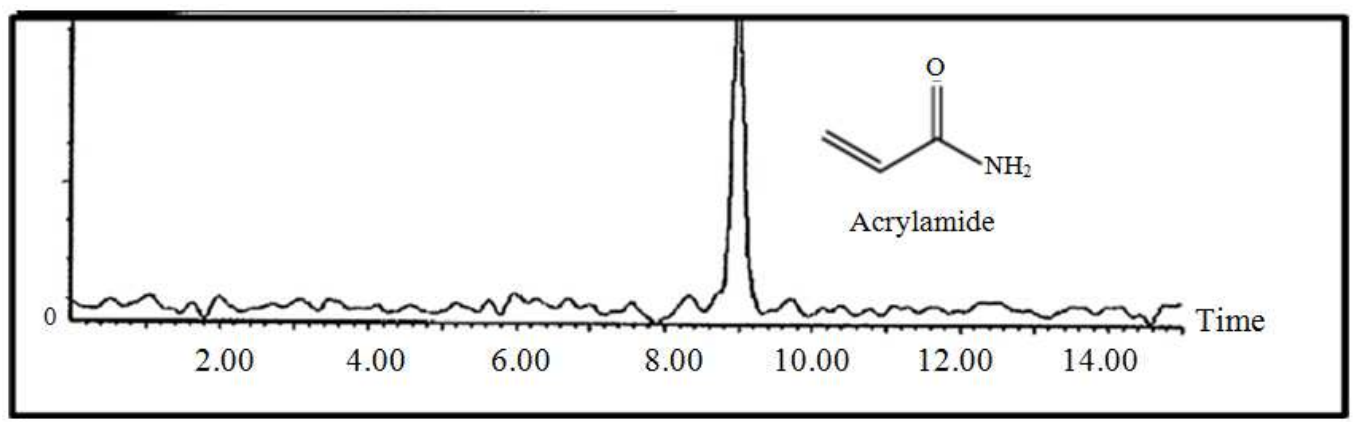

Fig. 1. The chemical structure of acrylamide and its chromatogram Source: Michalak, et al. 2013; Rosa et al., 2012

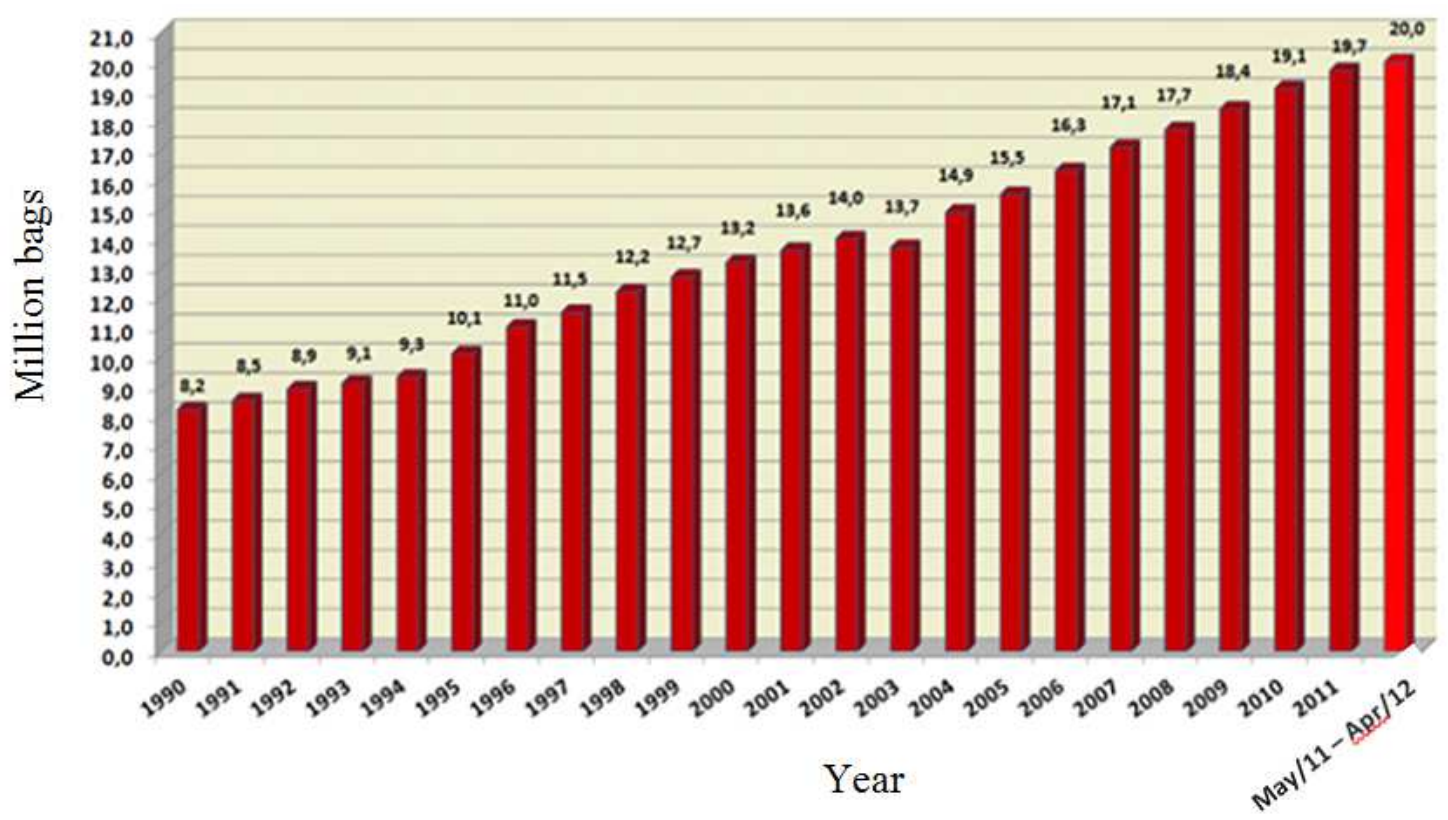

Fig. 2. Evolution of domestic coffee consumption in Brazil Source: ABIC (2012)

Certain workers are at particular risk of exposure, such as those engaged in heavy construction (including tunnels), coal mining, flocculant manufacturing and acrylamide manufacturing (Alves et al., 2010; Arisseto and Toledo, 2008; Neri, 2004; Felsot, 2002; Reynolds, 2002).

The presence of acrylamide in food such as coffee can pose risks to human health. Potential toxicological risks in foods are related not only to the presence of its precursors, asparagine and reducing sugars, but also to the concentrations of these compounds in the raw material, which can vary significantly between different species, cultivation practices and processing methods (Dias, 2008). Besides this, acrylamide has been considered neurotoxic and carcinogenic. It forms in carbohydrate-rich foods when they are fried, baked or roasted above $120^{\circ} \mathrm{C}$ (Arisseto and Toledo, 2008). According to the World Health Organization (WHO), the recommended daily limit for intake of acrylamide is 1 $\mu \mathrm{g} / \mathrm{kg} \mathrm{bw}$, or $60 \mu \mathrm{g}$, assuming body weight of $60 \mathrm{~kg}$ (WHO, 2005; SNFA, 2002).
Coffee is one of the most important beverages in the world because of its flavor and caffeine content. Since its consumption is high, it is important to study not only the chemical composition of the beans, but also the chemical changes during coffee roasting, because this can result in changes in quantity and quality of these pyrolysis products (Rosa et al., 2012; Dias, 2008).

World coffee consumption is increasing, particularly because of its growing popularity in China and India, two major consumers of tea. Additionally, coffee shops around the world are helping to spread consumption and creating demand for specialty coffees (Pardo et al., 2007).

The acrylamide content of coffee seems to depend not only on the botanical species but also to the type of processing. A comparison between the two most economically important species, Coffea arabica and $C$. canephora, showed that $C$. canephora, known as robusta, has a higher level of acrylamide, probably due to increased presence of asparagine in the green beans (Medeiros et al., 2011; Lantz et al., 2006). 
The formation of acrylamide in coffee occurs rapidly with the beginning of the roasting process and then slows as it approaches the maximum level (Alves et al., 2010). The acrylamide content in brewed coffee is highly variable, ranging from 0.5 to $4.21 \mu \mathrm{g}$ per $300 \mathrm{~mL}$ of coffee (Pedreschi et al., 2011).

The amount of acrylamide found in roasted coffee is relatively low compared to the potential formation resulting from the abundant presence of asparagine and reducing sugars (Dias, 2008). One factor that can contribute to relatively high levels of acrylamide is the number of defective and immature beans used in commercial production systems. Immature coffee beans contain significantly higher levels of free asparagine compared with mature ones (Guenther et al., 2007).

\section{Coffee Consumption}

\section{Coffee Consumption in Brazil}

Brazil's coffee consumption continues to increase. In the period between May 2011 and April 2012, ABIC recorded consumption of 19,975 million bags, an increase of $3.05 \%$ over the previous corresponding period (May 2010 to April 2011), was 19,383 million bags (Fig. 2). This increase was due to (i) growth of consumption outside the home, (ii) new and innovative products in the market, (iii) improved quality; and (iv) expanded supply of differentiated products (ABIC, 2012). Brazil is the world's leading coffee producer, with a market share of approximately 35\% (MAPA, 2012).

Brazilians are consuming more cups of coffee per day and diversifying the forms of drinking during the day, consuming espressos, cappuccinos and other combinations with milk in addition to the coffee brewed by filtering in homes (ABIC, 2012).

Brazil's per capita consumption remains one of the highest in the world. The champions of consumption, however, are still the Nordic countries-Finland, Norway and Denmark-with a volume of around $13 \mathrm{~kg} / \mathrm{per}$ capita/year (IBGE, 2012). Given the current low price of coffee arabica, differentiation has been an important alternative to increase competitiveness. The increasing concern with food safety and sustainability of agriculture are prompting growers to produce coffee with higher value (Arisseto et al., 2009).

According to Pereira et al. (2014) in Brazil, beverages contributed roughly $17 \%$ to total energy intake and caloric coffee beverages were the most commonly consumed beverage, regardless of age group.

\section{Coffee Consumption in Latin America}

Coffee consumption in Latin America has increased in recent years along with production. In Argentina, for example, coffee consumption is growing, especially of coffee in capsules, which increased by $30 \%$ (FAOSTAT, 2012).
In times of sharp decline in international coffee prices, big volumes produced and uncertainty about consumer demand in traditional markets, Brazil stands out as one of the emerging countries where sales continue to expand, a trend they should continue in the coming years (Anese et al., 2010).

Colombian coffee producers intend to open franchised coffee shops in Brazil and in other countries, as are already the case in the United States, Mexico and some countries in Europe. With this Colombian marketing action, coffee consumption in Latin American countries should increase, particularly of specialty coffees (for which Colombia is known). For example, in Brazil specialty coffees only account for $4 \%$ of the market (ABIC, 2012).

According to the FAOSTAT (2012), world coffee consumption is divided into five groups of countries according to average yearly per capita consumption: (i) between $8.0 \mathrm{~kg}$ and $12 \mathrm{~kg}$; (ii) between $4.1 \mathrm{~kg}$ and 8.0 $\mathrm{kg}$; (iii) between $2.4 \mathrm{~kg}$ and $4.5 \mathrm{~kg}$; (iv) between $0.8 \mathrm{~kg}$ and $2.4 \mathrm{~kg}$; and (v) less than $0.8 \mathrm{~kg}$ (FAOSTAT, 2012). Further according to data from the FAOSTAT (2012), the countries of Latin America are divided into three groups according to annual per capita coffee consumption: group 1: between $4.1 \mathrm{~kg}$ and $8.0 \mathrm{~kg}$ (Brazil, Argentina, Colombia and Costa Rica); group 2: between $2.4 \mathrm{~kg}$ and $4.5 \mathrm{~kg}$ (Guyana, French Guyana, Honduras, Suriname, Uruguay and Venezuela); and group 3: between $0.8 \mathrm{~kg}$ and $2.4 \mathrm{~kg}$ (Bolivia, Chile, Cuba, El Salvador, Ecuador, Guatemala, Haiti, Jamaica, Mexico, Nicaragua, Panama, Paraguay, Peru, Puerto Rico and Dominican Republic).

\section{Acrylamide Intake in Latin America}

\section{Acrylamide Intake Data}

The literature reports a range from 0.5 to $4.21 \mu \mathrm{g}$ of acrylamide per $300 \mathrm{~mL}$ of coffee (Pedreschi et al., 2011). The WHO recommends a daily maximum limit for acrylamide intake of $1 \mu \mathrm{g} / \mathrm{kg}$ bw/day (WHO, 2005). Thus, coffee contributes greatly to acrylamide intake by people who consume it (Medeiros et al., 2011).

\section{Acrylamide Intake from Coffee Consumption}

The figures on the estimated intake of acrylamide from coffee are presented in Table 1 . The results of the estimated annual intake of acrylamide from coffee consumption were calculated from the formula:

$$
\mathrm{y}=\mathrm{x} *(0.5 \text { to } 4.21) / 0.018
$$

where, $\mathrm{x}$ is the amount in $\mathrm{kg}$ of coffee per person per year consumed and $y$ is the amount of acrylamide intake in micrograms per person per year, reported in Table 1 . 
Table 1. Coffee Production, Consumption and Acrylamide Intake *Data adapted from ICO (2013) and FAOSTAT (2012)

\begin{tabular}{llll}
\hline Country & Coffee production* & Coffee consumption** $(\mathrm{kg})$ & Acrylamide Intake $(\mu \mathrm{g}) * * *$ \\
\hline Brazil & 50,826 & $4.1-8.0$ & $173.61-1461.80$ \\
Argentina & - & $4.1-8.0$ & $173.61-1461.80$ \\
Colombia & 9,500 & $4.1-8.0$ & $173.61-1461.80$ \\
Costa Rica & 1,700 & $4.1-8.0$ & $173.61-1461.80$ \\
Guyana & 5 & $2.4-4.5$ & $95.83-806.76$ \\
French Guyana & - & $2.4-4.5$ & $95.83-806.76$ \\
Honduras & 4,900 & $2.4-4.5$ & $95.83-806.76$ \\
Suriname & - & $2.4-4.5$ & $95.83-806.76$ \\
Uruguay & - & $2.4-4.5$ & $95.83-806.76$ \\
Venezuela & 2,300 & $2.4-4.5$ & $95.83-806.76$ \\
Bolivia & 115 & $0.8-2.4$ & $44.44-374.22$ \\
Chile & - & $0.8-2.4$ & $44.44-374.22$ \\
Cuba & 828 & $0.8-2.4$ & $44.44-374.22$ \\
El Salvador & 1,250 & $0.8-2.4$ & $44.44-374.22$ \\
Ecuador & 656 & $0.8-2.4$ & $44.44-374.22$ \\
Guatemala & 3,200 & $0.8-2.4$ & $44.44-374.22$ \\
Haiti & 325 & $0.8-2.4$ & $44.44-374.22$ \\
Jamaica & - & $0.8-2.4$ & $44.44-374.22$ \\
Mexico & 3,900 & $0.8-2.4$ & $44.44-374.22$ \\
Nicaragua & 1,500 & $0.8-2.4$ & $44.44-374.22$ \\
Panama & 110 & $0.8-2.4$ & $44.44-374.22$ \\
Paraguay & 20 & $0.8-2.4$ & $44.44-374.22$ \\
Peru & 4,133 & $0.8-2.4$ & $44.44-374.22$ \\
Puerto Rico & - & $0.8-2.4$ & $44.44-374.22$ \\
Dominican Republic & 550 & $0.8-2.4$ & $44.44-374.22$
\end{tabular}

*Coffee production per year - (1000 bags) **Estimated coffee consumption per year per person ***Estimated acrylamide intake per year per person

Table 2. Comparison of acrylamide intake by groups of countries in Latin America

\begin{tabular}{lll}
\hline Groups & Annual intake of acrylamide* & Daily intake of acrylamide* \\
\hline 1 & $173.61-1461.80 \mu \mathrm{g}$ & $0.47 \mu \mathrm{g}$ to $4.00 \mu \mathrm{g}$ \\
2 & $95.83-806.76 \mu \mathrm{g}$ & $0.26 \mu \mathrm{g}$ to $2.21 \mu \mathrm{g}$ \\
3 & $44.44-374.22 \mu \mathrm{g}$ & $0.12 \mu \mathrm{g}$ to $1.02 \mu \mathrm{g}$ \\
\hline
\end{tabular}

*Intake per person

The results of the estimated daily intake of acrylamide from coffee consumption were calculated from the formula:

$$
\mathrm{y}=\{[\mathrm{x} *(0.5 \text { to } 4.21)] / 0.018\} / 365
$$

where, $\mathrm{x}$ is the amount in $\mathrm{kg}$ of coffee per person per day consumed and $\mathrm{y}$ is the amount of acrylamide intake in micrograms per person per day, shown in Table 2.

The high consumption of coffee in some countries of Latin America generates concern over the consumption of this substance, since coffee is indicated as one of the main food sources of ingestion.

\section{Daily Acrylamide Intake through Coffee Consumption}

From the calculated data on acrylamide intake in Latin America, it was possible to estimate the daily intake of these populations from consuming coffee. The people from the countries in group 1 can ingest $0.47 \mu \mathrm{g}$ to $4.00 \mu \mathrm{g}$ of acrylamide daily, while those from group 2 countries take in $0.26 \mu \mathrm{g}$ to $2.21 \mu \mathrm{g}$ and those in group 3 countries ingest $0.12 \mu \mathrm{g}$ to $1.02 \mu \mathrm{g}$ (Table 2).
The high coffee consumption in some countries makes it a significant potential source of daily exposure to acrylamide, due to the use of roasted coffee beans for brewing. The likelihood of significant levels of acrylamide is high in all types of coffee (Jin et al., 2013; Senyuva and Gokmen, 2005). The concentration of acrylamide between arabica and robusta coffee varies with the amount of free asparagine present in the beans, which is slightly higher in the robusta varieties. With this, it is possible to affirm that the presence of acrylamide in robusta coffee is higher than in arabica (Dias, 2008).

\section{Epidemiological Evidence of Risk from Consumption of Acrylamide in Coffee and Strategies to Ameliorate Risk and/or Decontaminate Coffee}

Acrylamide, which is widely used worldwide in industry and can be produced by cooking and processing foods, has been found to be harmful to human beings. Brain Creatine Kinase (BB-CK) has been proposed as 
one of the important targets in the neurotoxicity of acrylamide. Sheng et al. (2009) studied the effects of acrylamide on human BB-CK activity, structure and the potential binding sites. Compared to creatine kinase from rabbits, Human Brain Creatine Kinase (HBCK) was fully inhibited at several-fold lower concentrations of acrylamide and exhibited distinct properties upon acrylamide-induced inactivation and structural changes. The highly conserved structure of CKs presented quite dissimilar responses, suggested that the effects of acrylamide might be isoenzyme- and species-specific. The binding sites of acrylamide were proposed to be located at the cleft between the $\mathrm{N}$ - and $\mathrm{C}$-terminal domains of $\mathrm{CK}$ and the affinities of the multiple sites might account for the slight difference in the sequence and structure of various CKs. This might be the structural basis for the different effects of acrylamide on various CKs. According to the authors, the results provided insight into the inhibitory effects and the possible ligand-binding mechanism of acrylamide on CK (Lu et al., 2009).

Pennisi et al. (2013) showed that acrylamide-exposed workers presented high prevalence of paresthesia in hands and legs, cramping in legs, poor blood circulation in fingers, skin irritation and peeling of skin on the hands, headache and breathlessness. The acrylamide induced neurotoxicity diminished ATP-ase activity while enhancing activity of acetilcholinesterase and dopamine depletion. Neurotoxicity is characterized by ataxia and skeletal muscle weakness. Numbness in hands and feet, fatigue and sweating of hands and feet are prominent symptoms of intoxication by this substance (Kopp and Dekant, 2009; Lu et al., 2009).

The foods that most contribute to consumer exposure to acrylamide are fried potatoes (16 to $30 \%$ of total exposure), potato chips (6 to $46 \%$ ), coffee (13 to $39 \%$ ), baked products, including cookies and crackers (10 to $20 \%$ ), and bread and toast (10 to $30 \%$ ) according to the type of processing used in the manufacture of these products (Dias, 2008).

There are great differences in the consumption of acrylamide-forming foods among populations from different countries besides wide variation in specific population groups (children, adolescents, adults, elderly, men versus women). This wide variation observed in the total levels of acrylamide in the diet in different food categories should stimulate the development of new approaches to reduce the acrylamide content of foods rich in this substance. (Keramate et al., 2011; Friedman and Levin, 2008).

According to Friedman and Levin (2008), coffee contributes to acrylamide intake in almost all population groups. This contribution varies demographically and the results indicate that for certain populations the amount of acrylamide received through consumption of coffee should be considered important.

Arisseto and Toledo (2008) conducted a study of the estimated intake of acrylamide in Brazil based on regional average consumption levels. This study showed that intake values of the country's five official regions were Midwest $(0.09 \mu \mathrm{g} / \mathrm{kg}$ per day), Northeast $(0.11$ $\mu \mathrm{g} / \mathrm{kg}$ per day), North $(0.12 \mu \mathrm{g} / \mathrm{kg}$ per day), Southeast $(0.15 \mu \mathrm{g} / \mathrm{kg}$ per day) and South $(0.20 \mu \mathrm{g} / \mathrm{kg}$ per day $)$. The foods that contributed most to the Brazilian exposure to acrylamide were fried potatoes, cookies/crackers and breads.

According to the European Food Safety Authority (EFSA) and the Joint FAO/WHO Expert Committee on Food Additives (JECFA) a margin of exposure (MOE) of 10000 would indicate low concern, underlining that the relatively low MOE for acrylamide calls for rapid and effective mitigation measures in order to lower consumer exposure (Bolger et al., 2010; Seal et al., 2008).

In March 2006, the European Commission and the Confederation of EU Food and Drink Industries (CIAA) organized a joint workshop to discuss current knowledge and achievements in the reduction of acrylamide levels (Konings et al., 2007). Acrylamide toxic exposure prevention should aim to avoid inhalation, dermal uptake or ingestion of food sources of this substance (Keramat et al., 2011). Yuan et al. (2014) evidenced that immersing potatoes in a $\mathrm{NaCl}$ and citric acid solution had a great influence on acrylamide formation in this food. Optimal immersion treatments can substantially reduce acrylamide content while reasonably retaining the sensory attributes of potato chips. Another way to reduce the formation of acrylamide is to use asparaginase, an enzyme that converts asparagine to aspartic acid. This procedure is used successfully in potato processing, where its application reduces the formation of acrylamide by $90 \%$ without causing sensory changes in the product. This strategy can also be used in coffee to reduce acrylamide formation (Dias, 2008; Wilson et al., 2006).

According to Claus et al. (2008), the most promising way to reduce acrylamide levels in cereal products is the addition of low molecular additives such as polyphenols. Polyphenols are a major contributor to the consumption of brewed coffee and the presence of antioxidants is important for a number of reasons, such as the prevention of lipid oxidation (Jin et al., 2013; Farah and Donangelo, 2006).

With the use of asparaginase, preliminary results in laboratory scale showed an acrylamide reduction of about $45 \%$, but the flavor was negatively altered, particularly of arabica coffee beans (Hidalgo et al., 2011). 


\section{Final Considerations}

According to the maximum limit set by the WHO of $1 \mu \mathrm{g}$ acrylamide per day per bw, for people in the countries of group 1, coffee makes a large contribution to the intake of acrylamide. Thus, the focus should be on reducing the levels of acrylamide in foods, since they are the predominant sources of this substance for some populations.

In recent years, there have been significant advances in the understanding of acrylamide and toxicity, including its formation mechanism and mitigation strategies. Some investigations have focused on the effect of various antioxidants and antioxidative extracts on acrylamide. Despite the presence of acrylamide in all types of roasted coffee, measures can be taken to lessen the formation of this substance and its presence can also be offset by oxidative balance. Polyphenols are a major contributor to the intake of the beverage and the presence of antioxidants is important for a number of factors, such as the prevention of lipid oxidation.

The data found in the literature and the findings in the present study evidence the importance of a balanced diet, as well the development of techniques that can reduce the formation of acrylamide in food sources such as coffee, to guarantee the safety of this important beverage.

\section{Conclusion}

The formation of acrylamide in coffee, the presence of its precursors, concentrations of these compounds in the raw material, coffee consumption and production in Latin America and potential toxicological risks to human health has been discussed in this review article. In this work, the countries of Latin America were divided into three groups according to annual per capita coffee consumption: group 1: between $4.1 \mathrm{~kg}$ and $8.0 \mathrm{~kg}$ (Brazil, Argentina, Colombia and Costa Rica); group 2: between $2.4 \mathrm{~kg}$ and $4.5 \mathrm{~kg}$ (Guyana, French Guyana, Honduras, Suriname, Uruguay and Venezuela); and group 3: between $0.8 \mathrm{~kg}$ and $2.4 \mathrm{~kg}$ (Bolivia, Chile, Cuba, El Salvador, Ecuador, Guatemala, Haiti, Jamaica, Mexico, Nicaragua, Panama, Paraguay, Peru, Puerto Rico and Dominican Republic). Coffee contributes to acrylamide intake in almost all population groups. From the calculated data on acrylamide intake in Latin America, it was possible to estimate the daily intake in the region's countries. According to the maximum limit set by the WHO of $1 \mu \mathrm{g}$ acrylamide per day per bw, for people in the countries of group 1, coffee makes a large contribution to the intake of acrylamide. In this way is mandatory to be focus on research to reduce the levels of acrylamide in foods, especially in coffee.

\section{Acknowledgement}

We thank to the Brazil's National Council for Scientific and Technological Development (CNPQ - N. 477265/2012-0), to the Fundação Carlos Chagas Filho de Amparo à Pesquisa do Estado do Rio de Janeiro (FAPERJ, n. E-26/110486/2014) and to the Brazilian Coffee Research Consortium for financial support.

\section{Author's Contributions}

Ana Carolina Vieira Porto: Participated in all steps of this review, analyzed the data and contributed to the writing of the manuscript.

Otniel Freitas-Silva: Designed the research plan and organized the study.

Jeane Santos da Rosa: Coordinated the dataanalysis and contributed to the writing of the manuscript.

Leda Maria Fortes Gottschalk: Designed the research plan and organized the study.

\section{Ethichs}

The authors have no conflict of interest.

\section{References}

ABIC, 2012. Consumo interno de café no Brasil 2011/2012. Associação Brasileira de Geografia e Estatística.

Alves, R., C. Soares, J. Fernandes, M. Beatriz and P. Oliveira, 2010. Acrylamide in espresso coffee: Influence of species, roast degree and brew length. Food Chem., 119: 929-934.

DOI: $10.1016 /$ j.foodchem.2009.07.051

Anese, M., M. Suman and M. Nicoli, 2010. Acrylamide removal from heated foods. Food Chem., 119: 791-794. DOI: $10.1016 / j$.foodchem.2009.06.043

Arisseto, M. and C. Toledo, 2008. Estimativa preliminar da ingestão de acrilamida no Brasil. Rev. Bras. Toxic., 21: 09-14.

Arisseto, M., C. Toledo, M. Govaert, J. Loco and S. Fraselle et al., 2009. Contribution of selected foods to acrylamide intake by a population of Brazilians adolescents. Food Addit. Contam., 42: 207-211.

Bolger, P., J. LeBlanc and R. Setzer, 2010. Application of the Margino $f$ Exposure (MoE) approach to substances in food that are genotoxic and carcinogenic. Food Cheml. Toxicol., 48: 525-533.

Claus, A., R. Carle and A. Schieber, 2008. Acrylamide in cereal products: A review. J. Cereal Sci., 47: 118-133. DOI: $10.1016 /$ j.jcs.2007.06.016

Dias, E.C., 2008. Perfil de aminoácidos nos frutos verdes do cafeeiro processados por via seca e via úmida. Dissertation, Universidade Federal de Lavras, Brazil, pp: 1-67.

FAOSTAT, 2012. World Coffee Production. Food and Agriculture Organization of the United Nations. 
Farah, A. and C. Donangelo, 2006. Phenolic compounds in coffee. Braz. J. Plant Physiol., 18: 23-36. DOI: $10.1590 / \mathrm{S} 1677-04202006000100003$

Felsot, A.S., 2002. Acrylamide angst: Another annoying distraction about food safety, Agrichemical and Environmental News: A Monthly Report on Environmental and Pesticide Related Issues. WSU, Washington, DC.

Friedman, M. and C. Levin, 2008. Review of methods for the reduction of dietary content and toxicity of Acrylamide. Food Chem., 56: 6113-6140.

DOI: $10.1021 / \mathrm{jf0} 0730486$

Friedman, M., 2003. Chemistry, biochemistry and safety of Acrylamide: A review. J. Agric. Food Chem., 51: 4504-4526. DOI: $10.1021 / \mathrm{jf030204+}$

Guenther, H., E. Anklam, T. Wenzl and R. Stadler, 2007. Acrylamide in coffee: Review of progress in analysis, formation and level reduction. Food Addit. Contam., 24: 60-70.

DOI: $10.1080 / 02652030701243119$

Hidalgo, F., R. Delgado and Z. Zamora, 2011. Positive interaction between amino and sulfhydryl groups for Acrylamide removal. Food Res. Int., 44: 1083-1087. DOI: 10.1016/j.foodres.2011.03.013

IBGE, 2012. Consumo Interno de Café no Brasil 2011/2012. Instituto Brasileiro de Geografia e Estatística.

ICO, 2013. Proposed framework for a global system to improve coffee quality. International Coffee Organization.

Jin, C., X. Wu and Y. Zhang, 2013. Relationship between antioxidants and acrylamide formation: A review. Food Res. Int., 51: 611-620.

DOI: 10.1016/j.foodres.2012.12.047

Keramat, J., A. LeBail, C. Prost and M. Jafari, 2011. Acrylamide in baking products: A review article. Food Bioprocess Technol., 4: 530-543.

DOI: $10.1007 / \mathrm{s} 11947-010-0495-1$

Konings, E.P., C. Hamlet and G. Thomspon, 2007. Acrylamide in cereal and cereal products: A review on progress in level reduction. Food Addit. Contam., 24: 47-59. DOI: 10.1080/02652030701242566

Kopp, E.K. and W. Dekant, 2009. Toxicokinetics of acrylamide in rats and humans following single oral administration of low doses. Toxicol. Appl. Pharmacol., 235: 135-142.

DOI: $10.1016 /$ j.taap.2008.12.001

Lantz, I., R. Ternité, J. Wilkens, K. Hoenicke and H. Guenther et al., 2006. Studies on acrylamide levels in roasting, storage and brewing of coffee. Mol. Nutr. Food Res., 50:1039-1046. DOI: $10.1002 / \mathrm{mnfr} .200600069$

Lu, Z.R., H.C. Zou, S.J. Park, D. Park and L. Shi et al., 2009. The effects of acrylamide on brain creatine kinase: Inhibition kinetics and computational docking simulation. Int. J. Biol. Macromol., 44: 128-132. DOI: 10.1016/j.ijbiomac.2008.11.003
MAPA, 2012. Brasil projeções do agronegócio 2011/2012 a 2021/2022 resumo executivo. Ministério da Agricultura, Pecuária e Abastecimento.

Medeiros, V., F. Mestdagh, C. Van Poucke, B. Kerkaert and N. Muer et al., 2011. Implementation of acrylamide mitigation strategies on industrial production of French fries: Challenges and pitfalls. J. Agric. Food Chem., 59: 808-906. DOI: $10.1021 / \mathrm{jf} 1042486$

Michalak, J., E. Gujska and A. Kuncewicz, 2013. RPHPLC-DAD studies on acrylamide in cereal-based baby foods. J. Food Comput. Anal., 32: 68-73. DOI: $10.1016 /$ j.jfca.2013.08.006

Neri, V., 2004. Acrilamida em Alimentos: Formação endógena e riscos à saúde. Revista de Nutrição., 23: 34-38.

Pardo, L.R., G.Y. Alvarez, T.D. Barral and A.M. Farré, 2007. Caffeine: A nutrient, a drug, or a drug of abuse. Adicciones, 19: 225-238.

Pedreschi, F., K. Kaack, K. Granby and J. Risum, 2011. Acrylamide reduction in potato chips by using commercial asparaginase in combination with conventional blanching. Food Sci. Technol., 44: 1473-1476. DOI: 10.1016/j.lwt.2011.02.004

Pennisi, M., G. Malaguarnera, V. Puglisi, L. Vinciguerra and M. Vacante et al., 2013. Neurotoxicity of acrylamide in exposed workers. Int. J. Environ. Res. Public Health, 10: 3843-3854. DOI: $10.3390 /$ ijerph10093843

Pereira, R.A., A.M. Souza, K.J. Duffey, R. Sichieri and B.M. Popkin, 2014. Beverage consumption in Brazil: results from the first National Dietary Survey. Public Health Nutr., 27: 1-9. DOI: $10.1017 / \mathrm{S} 1368980014001657$

Reynolds, T., 2002. Acrylamide and cancer: Tunnel leak in sweden prompted studies. J. Nat. Cancer Inst., 94: 876-878. DOI: 10.1093/jnci/94.12.876

Rosa, J., O. Freitas-Silva, S. Pacheco, R. Godoy and C. Rezende, 2012. LC-MS based screening and targeted profiling methods for complex plant: coffee a case study. Curr. Drug Metab., 13: 1244-1250. DOI: $10.2174 / 138920012803341410$

Seal, C., A. Mul, G. Eisenbrand, A. Haverkor and K. Franke et al., 2008. Risk-benefit considerations of mitigation measures on acrylamide content of foodsa case study on potatoes, cereals and coffee. Br. J. Nutr., 99: S1-S46.

DOI: $10.1017 / \mathrm{S} 0007114508965314$

Senyuva, H. and V. Gokmen, 2005. Study of acrylamide in coffee using an improved liquid chromatography mass spectrometry method: Investigation of colour changes and acrylamide formation in coffee during roasting. Food Addit. Contam., 22: 214-220.

DOI: $10.1080 / 02652030500109834$ 
Sheng, O., H. Zou, Z. Lu, F. Zou and Y. Park et al., 2009. Effects of acrylamide on the activity and structure of human brain creatine kinase. Int. J. Molecular Sci., 10: 4210-4222.

DOI: $10.3390 /$ ijms 10104210

SNFA, 2002. Acrylamide in food. Swedish National Food Agency.

WHO, 2005. Acrylamide in food: Frequently asked questions. World Health Organization.

Wilson, K.M., E.B. Rimm, K.M. Thompson and L.A. Mucci, 2006. Dietary acrylamide and cancer risk in humans: A review. J. Verbraucherschutz und Lebensmittelsicherheit, 1: 19-27.

DOI: $10.1007 / \mathrm{s} 00003-006-0005-6$
Yuan, Y., Z. Huanjie, M. Yutian and Z. Hong, 2014. Study on the methods for reducing the acrylamide content in potato slices after microwaving and frying processes. RSC Adv., 4: 1004-1009.

DOI: $10.1039 / C 3 R A 44151 B$

Zhang, Y., G. Zhang and Y. Zhang, 2005. Occurrence and analytical methods of acrylamide in heat-treated foods: Review and recent developments. J. Chromatography A, 1075: 1-21.

DOI: $10.1016 /$ j.chroma.2005.03.123 